\title{
Primary Antimitochondrial Activity of the Cancer Drug Methylglyoxal Bis(guanylhydrazone) in Yeast Cells
}

\author{
By EDWARD S. DIALA, $\dagger$ IVOR H. EVANS $\ddagger$ AND DAVID WILKIE* \\ Department of Botany and Microbiology, University College London, \\ Gower Street, London WC1E $6 B T$
}

(Received 5 November 1980; revised 11 February 1980)

\begin{abstract}
Primary action of methylglyoxal bis(guanylhydrazone) (MGBG) on the yeast mitochondrial system was demonstrated by (1) selective inhibition of cell growth in non-fermentable medium, (2) blockage of mitochondrial synthesis of cytochromes $a a_{3}$ and $b$ and (3) ultrastructural aberration. The drug caused extensive deletions in mitochondrial DNA detected by an increase in the frequency of the mitochondrial mutant petite but had little or no effect on cell viability. Growth inhibition by MGBG was antagonized by spermidine but neither the polyamine nor MGBG had any effect on growth inhibition by ethidium bromide. Strains showed no cross-correlation in their tolerance to MGBG and ethidium bromide.
\end{abstract}

\section{INTRODUCTION}

The antiproliferative drug methylglyoxal bis(guanylhydrazone) (MGBG) (NSC-32946) inhibits the growth of certain mouse tumours and also possesses clinical activity against acute myelocytic leukaemia and murine leukaemia (Mihich, 1975). The drug is believed to be a structural analogue of the polyamine spermidine and its cytotoxicity may result from interference with polyamine metabolism but this is not clearly established (Heby et al., 1977). Pathak et al. (1977) have demonstrated that MGBG has an effect on the mitochondrial ultrastructure of cultured mouse leukaemia L1210 cells causing extensive swelling of the organelle, loss of internal structure and increase in matrix density. These authors claim that the mitochondrial damage is primary, preceding growth inhibition by about $12 \mathrm{~h}$ and causing no concomitant loss of cell viability. In addition, further evidence of MGBG-induced mitochondrial damage has been seen in several human and murine cell types (MiklesRobertson et al., 1979; Diala, 1978).

In mammalian cell systems it is difficult to prove primary antimitochondrial activity but the yeast cell is most useful in establishing this point. We report here on the activity of MGBG in this system.

\section{METHODS}

Organisms. Twenty-one haploid strains of Saccharomyces cerevisiae were used.

Media. Liquid media contained $1 \%(\mathrm{w} / \mathrm{v})$ yeast extract (Difco) and either $2 \%(\mathrm{w} / \mathrm{v})$ D-glucose (YED) or $4 \%$ (v/v) glycerol (YEG) as carbon source. For solid media, $2 \%(w / v)$ agar (Difco) was added.

Chemicals. Methylglyoxal bis(guanylhydrazone) (MGBG) was obtained from the Aldrich Chemical Co. Ltd, Milwaukee, Wis., U.S.A., spermidine from Sigma and ethidium bromide from BDH.

Determination of growth inhibition. The inhibitory activity of MGBG was examined on a series of YED and YEG agar plates containing MGBG in concentrations ranging from $0 \cdot 1$ to $10 \mathrm{mg} \mathrm{ml}^{-1}$. Plates were

$\dagger$ Present address: St Mary's Hospital Medical School, University of London, Paddington, London W2 1PG.

$\ddagger$ Present address: Department of Plant Biology and Microbiology, Queen Mary College, University of London, Mile End Road, London E1 4NS. 
inoculated with a suspension of each of the 21 strains using a multiple drop-inoculation device (Wilkie, 1972), each drop of inoculum containing approximately $10^{4}$ cells. In tests in liquid medium, shake flasks with sidearms were used, each flask containing $20 \mathrm{ml}$ of either YED or YEG medium with MGBG present at a concentration of $0.25,0.5,1,2$ or $5 \mathrm{mg} \mathrm{ml}^{-1}$ in YED and $0.1,0.25$ or $2 \mathrm{mg} \mathrm{m}^{-1}$ in YEG. Turbidities of the cultures were measured in an EEL colorimeter (EEL units) at appropriate intervals and then growth curves were constructed. The effect of spermidine on the inhibitory activity of MGBG was studied by adding the polyamine from a stock aqueous solution to the drug-containing media. The effect of spermidine up to $0.2 \mathrm{mg} \mathrm{ml}^{-1}$ on growth inhibition by $25 \mu \mathrm{g}$ ethidium bromide $\mathrm{ml}^{-1}$ in YEG agar was also investigated. Finally, sub-inhibitory concentrations of MGBG were added to cultures in which growth was inhibited by ethidium bromide to determine whether there was any interaction between the two drugs.

Inhibition of mitochondrial protein synthesis. Cells were grown to stationary phase in the presence of MGBG in YED liquid medium. Concentrations of MGBG used were inhibitory in YEG medium. Cells were harvested, washed and suspended in high concentrations (approx. $10^{8}$ cells $\mathrm{ml}^{-1}$ ) in cuvettes which were placed in a Pye Unicam recording spectrophotometer. Absorption spectra were recorded at room temperature against a blank of tissue paper.

Effects on mitochondrial DNA replication. The petite mutation was used to measure genetic lesions in organelle DNA (Bernardi, 1979). Petite mutants were identified as small, white colonies on YEDagar which failed to grow when transferred to YEG agar by velvet pad. Single cells, both normal and petite, were isolated by micromanipulation carried out on YED agar blocks containing $0,50,300$ and $400 \mu \mathrm{g} \mathrm{MGBG} \mathrm{ml}^{-1}$ and their rate of division was monitored by light microscopy. Petite mutants from both treated and untreated cultures were examined.

Measurement of respiration. The oxygen uptake of whole yeast cells was measured polarographically with a Clark-type oxygen electrode (type 4004; Yellow Springs Instrument Co., Ohio, U.S.A.) connected to an amplifier and a flat-bed chart recorder. Cells were suspended in the electrode chamber (fixed volume of $2 \mathrm{ml}$ ) which contained $50 \mathrm{~mm}-N$-2-hydroxyethylpiperazine- $N^{\prime}$-2-ethanesulphonic acid (HEPES) buffer, $\mathrm{pH} 6 \cdot 8$, maintained at $30^{\circ} \mathrm{C}$.

Electron microscopy. Cell cultures were centrifuged, washed twice in distilled water, and fixed in $5 \%$ (w/v) aqueous $\mathrm{NaMnO}_{4}$ (unbuffered) for $90 \mathrm{~min}$ at room temperature. Cells were then washed twice in distilled water and resuspended in warm $\left(50^{\circ} \mathrm{C}\right.$ ) Noble Agar (Difco) which, after setting, was cut into $1 \mathrm{~mm}$ squares. These blocks were then progressively dehydrated in a graded ethanol series, followed by embedding in an epoxy/Araldite resin mixture (EMscopes Laboratories, Kent). Sections were routinely post-stained with $2 \%(\mathrm{w} / \mathrm{v})$ aqueous solutions of uranyl acetate and of lead citrate and examined in either a Hitachi HS-9 or an AEI-801 electron microscope.

\section{RESULTS}

\section{Growth inhibitory activity of $M G B G$}

All strains when tested on the YED/YEG agar-drug series were more sensitive to MGBG on the non-fermentable (YEG) medium indicating selective antimitochondrial activity. The minimum inhibitory concentration (m.i.c.) was strain-dependent. The average m.i.c. on YED was $5 \mathrm{mg} \mathrm{ml}^{-1}$ and on YEG was $1.8 \mathrm{mg} \mathrm{ml}^{-1}$. One of the strains under test (A30) was studied in more detail, and growth curves obtained in liquid medium with this strain confirmed the initial observation: the concentration of MGBG required to cause $50 \%$ inhibition of growth in YED medium was more than three times that for comparable inhibition in YEG medium (here, as for inhibitors generally, potency was greater in liquid than on solid medium). Inhibition by MGBG was overcome and growth was restored in all strains tested by the presence of spermidine at appropriate concentrations. For example, strain A30, totally inhibited on YEG agar in the presence of $0.5 \mathrm{mg} \mathrm{MGBG} \mathrm{ml}^{-1}$, showed good growth when $0 \cdot 1 \mathrm{mg}$ spermidine $\mathrm{ml}^{-1}$ was also present in the medium. Reversal of MGBG inhibition in strains $A 30$ and $41 / 161$ by spermidine was examined in more detail in liquid culture and the results with A30 are shown in Fig. 1. Similar results were obtained with strain 41/161. The results indicated that MGBG was an antagonist of spermidine. Inhibition of growth of all strains in YEG medium by ethidium bromide, a well-known and highly selective inhibitor of mitochondrial biogenesis, was unaffected by the presence of spermidine. The addition of MGBG had, likewise, no detectable effect on ethidium bromide inhibition. Also, there was no cross-correlation in strain tolerance to ethidium bromide and MGBG indicating that the drugs have different modes of action. In other words, the phenạnthrene did not seem to 


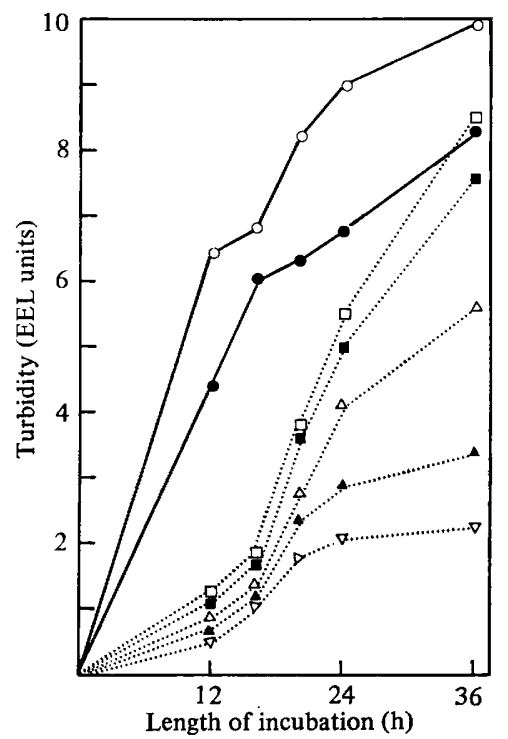

Fig. 1

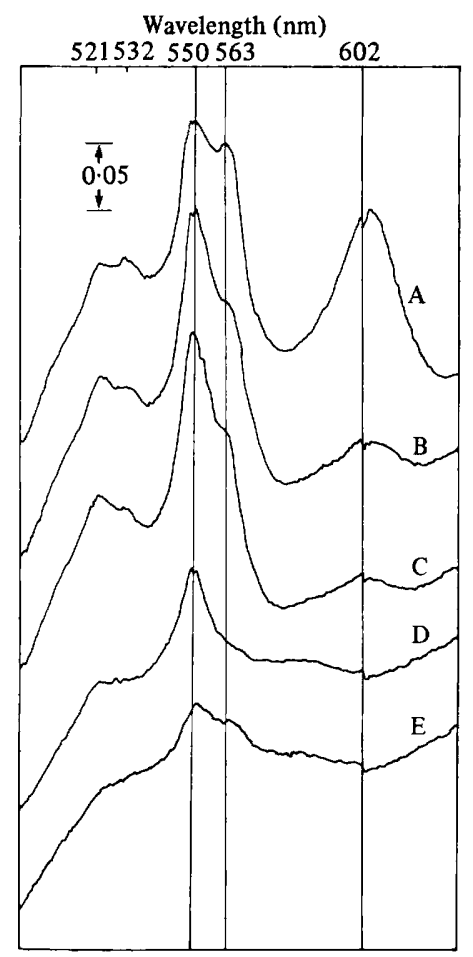

Fig. 2

Fig. 1. Growth of $S$. cerevisiae strain A30 at $30^{\circ} \mathrm{C}$ in yeast extract liquid medium containing either $2 \%(\mathrm{w} / \mathrm{v})$ glucose $(-)$ or $4 \%(\mathrm{v} / \mathrm{v})$ glycerol $(\cdots . .$.$) in the presence of MGBG and/or spermidine.$ Glucose cultures: $\bigcirc$, control; $\bigcirc, 250 \mu \mathrm{g} \mathrm{MGBG} \mathrm{ml}^{\mathbf{1}}$. Glycerol cultures: $\square$, control; $\square, 100 \mu \mathrm{g}$ spermidine $\mathrm{ml}^{-1} ; \Delta, 100 \mu \mathrm{g} \mathrm{MGBG} \mathrm{ml}^{-1} ; \nabla, 250 \mu \mathrm{g} \mathrm{MGBG} \mathrm{ml}^{-1} ; \Delta, 100 \mu \mathrm{g} \mathrm{MGBG} \mathrm{ml}^{-1}$ plus $100 \mu \mathrm{g}$ spermidine $\mathrm{ml}^{-1}$.

Fig. 2. Absorption spectra of whole $S$. cerevisiae cells in the cytochrome-absorbing region of 500 to $630 \mathrm{~nm}$. The vertical bar represents 0.05 absorbance units and the major absorption peaks for cytochromes $a a_{3}, b$ and $c$ are, respectively, at 602,563 and $550 \mathrm{~nm}$ ( $\alpha$ peaks). Absorption peaks at 521 and $532 \mathrm{~nm}$ represent the $\beta$ peaks for cytochromes $c$ and $b$, respectively. Strain A30 was grown to stationary phase $(44 \mathrm{~h})$ in liquid YED medium containing MGBG $\left(\mathrm{mg} \mathrm{ml}^{-1}\right): \mathrm{A}$, none; $\mathrm{B}, 0.05$; C, $0 \cdot 1 ; \mathrm{D}, 0.75 ; \mathrm{E}, 1 \cdot 0$.

behave as an analogue of spermidine, although this has been suggested by Heby et al. (1977) and Mikles-Robertson et al. (1979). Spermidine itself was stimulatory at $100 \mu \mathrm{g} \mathrm{ml}^{-1}$ (Fig. 1) and slightly inhibitory at $200 \mu \mathrm{g} \mathrm{ml}^{-1}$.

\section{Effect of $M G B G$ on mitochondrial protein synthesis}

The absorption spectra, in the cytochrome-absorbing region, of $S$. cerevisiae cells grown in the presence of MGBG revealed small or absent peaks at $602 \mathrm{~nm}$ (cytochrome $a a_{3}$ ) and $563 \mathrm{~nm}$ (cytochrome $b$ ), i.e. failure of mitochondrial protein synthesis, while the peak at $550 \mathrm{~nm}$ (cytochrome $c$ ) was largely unaffected, i.e. continuance of cytoplasmic protein synthesis (Fig. 2). Since the cells were growing and dividing under these conditions, this showed that MGBG at the concentrations used had no significant effect on general cellular processes in YED medium although at $1 \mathrm{mg} \mathrm{ml}^{-1}$ there was some suppression of cytochrome $c$ synthesis (Fig. 2).

\section{Effect of $M G B G$ on the ultrastructure of $S$. cerevisiae}

Under the electron microscope a typical $S$. cerevisiae cell is seen to contain numerous well-defined peripherally located spherical-to-cylindrical shaped mitochondria in which 

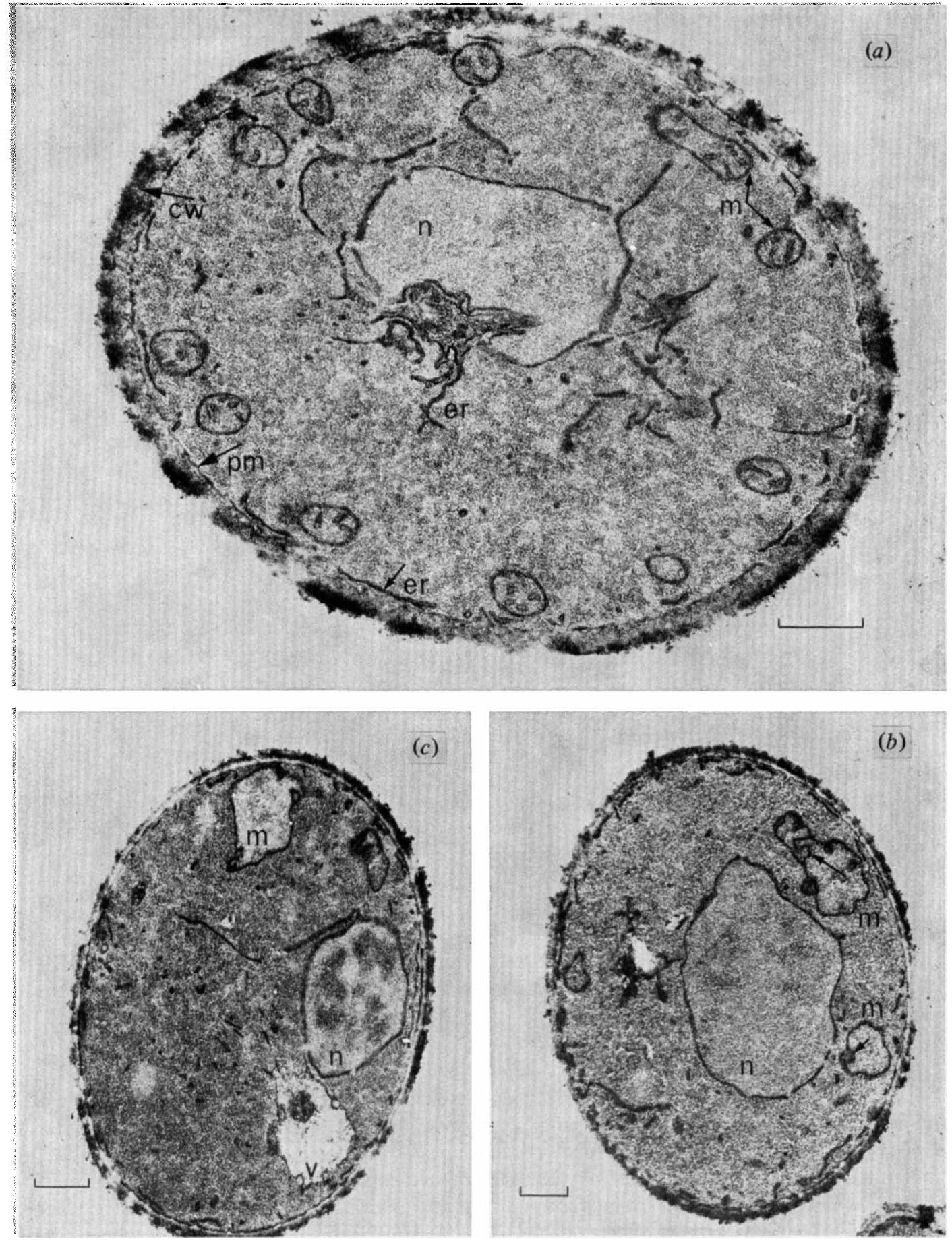

Fig. 3. Ultrastructural effects of MGBG on yeast cells. Saccharomyces cerevisiae strain A30 was grown at $30^{\circ} \mathrm{C}$ in liquid shake YED cultures with or without MGBG. m, mitochondrion; $n$, nucleus; $\mathrm{cw}$, cell wall; pm, plasma membrane; er, endoplasmic reticulum; v, vacuole. All bar markers represent $500 \mathrm{~nm}$.

(a) Control cells (no MGBG) grown to stationary phase (44 h). (b) Cells grown in the presence of $250 \mu \mathrm{g} \mathrm{MGBG} \mathrm{ml}^{-1}$ for $20 \mathrm{~h}$; the mitochondria are swollen and there are few inner membrane cristae (arrows). (c) Cells grown in the presence of $500 \mu \mathrm{g} \mathrm{MGBG} \mathrm{ml}^{-1}$ for $44 \mathrm{~h}$; the distorted mitochondria appear swollen and electron translucent. 
Table 1. Induction of the mitochondrial mutation petite by MGBG in S. cerevisiae

Strains were grown in liquid YED medium (with or without MGBG) at $30^{\circ} \mathrm{C}$ for $2 \mathrm{~d}$. Cell suspensions were counted in a haemocytometer and samples were plated on YED agar medium. Plates were incubated for 5 to $7 \mathrm{~d}$ before petite colony frequencies were assessed. Results given are the average of three experiments, with standard deviations. The total numbers of colonies examined are shown in parentheses.

\begin{tabular}{ccc}
$\begin{array}{c}\text { MGBG } \\
\text { concn } \\
\left(\mathrm{mg} \mathrm{ml}^{-1}\right)\end{array}$ & No. of petite colonies per 1000 colonies \\
\cline { 2 - 3 } & Strain A30 & Strain 41/161 \\
$1 \cdot 0$ & $9 \pm 0 \cdot 1(1846)$ & $12 \pm 0 \cdot 1(2753)$ \\
$2 \cdot 5$ & $22 \pm 0 \cdot 5(1584)$ & $20 \pm 1 \cdot 8(2718)$ \\
$3 \cdot 5$ & $39 \pm 4 \cdot 5(1956)$ & $46 \pm 8 \cdot 2(2261)$ \\
$5 \cdot 0$ & Not tested & $49 \pm 1 \cdot 1(1536)$ \\
& & $158 \pm 20 \cdot 7(1120)$
\end{tabular}

distinct plate-like cristae are evident (Fig. $3 a$ ). In general appearance, the cytoplasm is homogeneous in density and the plasma membrane, usually found closely pressed to the cell wall, is conspicuous and has a smooth or convoluted appearance. The single nucleus is centrally placed in the cell with the endoplasmic reticulum proliferating from the nuclear membrane to become associated with the plasma membrane.

In yeast cells treated with MGBG, marked changes occurred in the structure of the mitochondria. After exposure to $250 \mu \mathrm{g} \mathrm{MGBG} \mathrm{ml}^{-1}$ the mitochondria were conspicuously swollen and the inner membrane cristae were shortened and confined to the periphery of the organelle (Fig. $3 b$ ). This feature was strikingly similar to the state of the mitochondria in L1210 cells treated for $24 \mathrm{~h}$ with $10 \mu \mathrm{M}-\mathrm{MGBG}$ described by Pathak et al. (1977) and in those of human fibroblasts exposed for $48 \mathrm{~h}$ to $10 \mu \mathrm{M}-\mathrm{MGBG}$. Mitochondrial aberrations of this kind in other yeasts, usually after treatment with antibiotics that preferentially inhibit mitochondrial protein synthesis, e.g. chloramphenicol, have also been reported (Marchant \& Smith, 1968). Following exposure to $500 \mu \mathrm{g} \mathrm{MGBG} \mathrm{ml}^{-1}$, extensive swelling of the mitochondria occurred with almost complete loss of inner membrane cristae and a decrease in the density of the matrix (Fig. 3c). Again, this type of ultrastructural aberration has been seen in mammalian tissue culture systems (Mikles-Robertson et al., 1979).

\section{Effect of $M G B G$ on mitochondrial DNA replication}

Cells treated with MGBG and plated on YED medium gave a slightly higher proportion of petite colonies than did untreated control cells at the lower concentrations of drug tested. At $5 \mathrm{mg} \mathrm{ml}^{-1}$, the frequency of petite colonies was correspondingly greater (Table 1). For all levels of treatment, cells had a high viability $(>90 \%)$ with little evidence of any killing effect by MGBG.

When rates of division of isolated cells were determined, in all cases petite cells had a slower rate of division than normal cells in the presence of MGBG, showing that the mitochondrial mutants did not have a selective advantage over normal cells in the presence of the drug. This indicated that the increased frequencies of petite mutants from treated cultures (Table 1) were due to induction by the drug and were, in fact, an underestimate of the mutagenic effect of MGBG on the yeast mitochondrial system.

\section{Effect of $M G B G$ on respiration}

Whereas the rates of oxygen uptake of control A30 cells were normal, those of MGBGtreated cells were much reduced, being as low as $10 \%$ of the controls. The amounts by which oxygen uptake was reduced correlated with the drug concentrations. When spermidine was present in MGBG-containing medium, respiratory activity was restored and approached that of normal cells. 


\section{DISCUSSION}

There is evidence that spermidine complexes with DNA in regulating the activity of this molecule (Cohen, 1978). It is also claimed that polyamines have a controlling influence on mitochondrial metabolism (Chaffee et al., 1979). The results reported here suggest that MGBG is a spermidine analogue and as such could be acting to block spermidine synthesis or to compete with spermidine for DNA-binding sites. In either case, impairment of DNA transcription and replication might be expected and this is apparently what is occurring in yeast cells, but selectively in the mitochondria. Why the mitochondrion should be the primary target is not clear but it may be due to organizational differences between mitochondrial DNA and nuclear DNA - the former is a circular molecule and is not complexed with packaging proteins as is nuclear DNA. There are other features of mitochondria which may make them more vulnerable to toxic agents and these are discussed by Egilsson et al. (1979). Many drugs used in cancer chemotherapy besides MGBG may have primary antimitochondrial activity. Evidence leading to this conclusion is presented and discussed in detail by Wilkie (1979).

The authors wish to thank Mrs Doreen Collier for excellent technical assistance, Professor W. G. Chaloner and Mr Graham Lawes for help in providing electron microscope facilities at Birkbeck College, University of London. The work was supported by a grant from the Cancer Research Campaign to D.W.

\section{REFERENCES}

BERNARDI, G. (1979). The petite mutation in yeast. Trends in Biochemical Sciences 4, 197-201.

Chaffee, R. R. J., ARINe, R. M. \& Rochelle, R. H. (1979). The possible role of intracellular polyamines in mitochondrial metabolic regulation. Biochemical and Biophysical Research Communications 86, 293-299.

CoHen, S. S. (1978). What do the polyamines do? Nature, London 274, 209-210.

Diala, E. S. (1978). Mitochondrial ultrastructure in Saccharomyces cerevisiae: effects of mutations and inhibitors. Ph.D. thesis, University of London.

Egrusson, V., Evans, I. H. \& Wilkie, D. (1979). Toxic and mutagenic effects of carcinogens on the mitochondria of Saccharomyces cerevisiae. Molecular and General Genetics 174, 39-46.

Heby, O., Marton, L. J., Wilson, C. B. \& Gray, J. W. (1977). Effect of methylglyoxal-bis(guanylhydrazone), an inhibitor of spermidine and spermine synthesis, on cell cycle traverse. European Journal of Cancer 13, 1009-1017.

Marchant, R. \& SMith, D. G. (1968). Membranous structures in yeast. Biological Reviews 43, 459-480.
MiHICH, E. (1975). Bisguanylhydrazones. In Handbook of Experimental Pharmacology, vol. 38/2, pp. 766-788. Edited by A. S. Sartorelli \& D. G. Johns. New York: Springer-Verlag.

Mikles-Robertson, F., Feuerstein, B., Dave, C. \& PORTER, C. W. (1979). The generality of methylglyoxal bis(guanylhydrazone) induced mitochondrial damage and the dependence of this effect on cell proliferation. Cancer Research 39, 1919-1926.

Pathak, S. N., Porter, C. W. \& Dave, C. (1977). Morphological evidence for an antimitochondrial action by methylglyoxal-bis(guanylhydrazone). Cancer Research 37, 2246-2250.

WILKIE, D. (1972). The yeast cell in anti-mitochondrial activity of drugs. Medical and Biological Illustration 22, 119-124.

WILKIE, D. (1979). Antimitochondrial drugs in cancer chemotherapy: preliminary communication. Journal of the Royal Society of Medicine 72, 599-601. 